\title{
Effects of active immunization against a synthetic peptide sequence of the inhibin $\alpha$-subunit on plasma gonadotrophin concentrations, ovulation rate and lambing rate in ewes
}

\author{
J. H. M. Wrathall ${ }^{1}$, B. J. McLeod ${ }^{2}$, R. G. Glencross ${ }^{2}$ and P. G. Knight ${ }^{1 *}$ \\ 'Department of Biochemistry and Physiology, University of Reading, PO Box 228, Reading RG6 \\ 2AJ, UK; and ${ }^{2} A F R C$ Institute for Grassland and Animal Production, Hurley, \\ Maidenhead SL6 5LR, UK
}

\begin{abstract}
Summary. Thirty adult Mule (Blue-faced Leicester $\times$ Swaledale) ewes were actively immunized against a synthetically produced peptide corresponding to the $\mathrm{N}$-terminus of the $\alpha$-subunit of bovine inhibin conjugated to tuberculin purified protein derivative (PPD). Primary immunization in the late anoestrous period was followed by two booster injections at 5 week intervals. Control groups were either not immunized ( $n=$ 15 ) or received PPD only $(n=15)$. Ten days after the second booster, oestrus was synchronized using progestagen sponges and ovulation rate was assessed by laparoscopy on days $9-10$ of the cycle. Blood samples were taken at the time of each immunization and immediately before laparoscopy. Ewes were mated with fertile rams in midNovember and the resulting conception, pregnancy and lambing rates monitored. All inhibin-immunized ewes generated antibodies that bound ${ }^{125}$ I-labelled native bovine inhibin $\left(M_{\mathrm{r}} 32000\right)$, and their plasma follicle-stimulating hormone (FSH) concentrations after the second booster were significantly higher than the preimmunization values $(30 \% ; P<0.001)$ and the corresponding value in the controls $(25 \%$; $P<0.025)$. Inhibin immunization was associated with a $90 \%$ increase in ovulation rate $(P<0.005)$ and had no adverse effect on conception rate $(100 \%)$, pregnancy rate $(100 \%)$ or length of gestation (146 days). However, only a $37 \%$ increase $(P<0.05)$ in lambing rate was recorded for inhibin-immunized ewes, indicating a higher incidence of wastage of ova, or embryos, or both, in these ewes. As a consequence of the increased litter size, mean live birthweight of lambs was significantly lower $(18 \% ; P<0.001)$ in the inhibin-immunized group and a higher proportion of the lambs born to inhibinimmunized ewes $(15.4 \%$ compared with $0.02 \%$ in controls) were stillborn. Stillborn lambs weighed considerably less $(38 \% ; P<0.001)$ than viable lambs. In terms of the number of viable lambs produced, there was no significant difference between the inhibin-immunized and control group. Although this study confirms the effectiveness of inhibin immunization using a synthetic peptide-based vaccine as a reliable method for increasing ovulation rate in sheep, the results indicate the limitations of this technique for further increasing viable litter size in 'improved' breeds of relatively high inherent prolificacy.
\end{abstract}

Keywords: inhibin; immunization; sheep; ovulation; litter size; FSH

\section{Introduction}

Various strategies have been used to increase prolificacy in sheep and other domesticated species. In addition to selective breeding programmes (Bradford, 1985), a number of nongenetic methods have

*Requests for offprints. 
received considerable attention including administration of exogenous gonadotrophins such as equine chorionic gonadotrophin (Gheraradi \& Lindsay, 1980), autoimmunization against ovarian steroids by active (Scaramuzzi \& Hoskinson, 1984) or passive (Land et al., 1982) immunization and, more recently, autoimmunization against inhibin. Inhibin is a gonadal glycoprotein hormone which exerts a selective, suppressive effect on the secretion of pituitary FSH (Ying, 1988). As such, it would be anticipated that immunoneutralization of endogenous circulating inhibin would lead to an increase in plasma FSH concentrations which could promote ovarian hyperstimulation, perhaps culminating in an increased ovulation rate. Experiments involving active immunization of sheep against various inhibin-containing preparations including partially purified bovine follicular fluid (Henderson et al., 1984; O'Shea et al., 1984; Cummins et al., 1986; Al-Obaidi et al., 1987), recombinant DNA-derived preparations of the inhibin $\alpha$-subunit (Forage et al., 1987; Tsonis et al., 1989; Mizumachi et al., 1990) and chemically synthesized fragments of inhibin (Wrathall et al., 1990) have provided convincing evidence to support this theory and have proved conclusively that immunoneutralization of endogenous inhibin can promote a marked increase (2-4-fold) in ovulation rate. However, very little information (Tsonis et al., 1989) is available regarding the impact of inhibin immunization on other critical stages of the reproductive process (including the ability of the ewe to display oestrus, mate, conceive and gestate) and whether the observed increase in ovulation rate is actually reflected by an increase in viable litter size.

The objectives of the present study were (i) to confirm the effectiveness of a synthetic peptidebased inhibin vaccine in generating antibodies to inhibin, raising plasma FSH and increasing ovulation rate in a different (and more typical UK lowland) breed of sheep from that used in our initial study (Wrathall et al., 1990); and (ii) to establish the subsequent effect of inhibin immunization on conception, pregnancy and lambing rates in sheep maintained, as closely as possible, under normal husbandry conditions.

\section{Materials and Methods}

\section{Preparation of immunogen}

A synthetic peptide, corresponding to the N-terminal sequence (1-29) of the $\alpha$-subunit of bovine inhibin (bI $\alpha(1-$ 29)-Tyr30, custom-synthesized by Protein and Peptide Research Consultants, Reading, Berks, UK) was conjugated to tuberculin purified protein derivative (PPD; MAFF Central Veterinary Laboratory, Weybridge, Surrey, UK) at a ratio of $1: 3(\mathrm{w} / \mathrm{w})$ as described by Wrathall $e t$ al. (1990). The resulting conjugate was divided into $1.5 \mathrm{ml}(4 \mathrm{mg}$ conjugate) aliquots and stored at $-20^{\circ} \mathrm{C}$.

\section{Animals and treatments}

The animals used in the study formed part of the University of Reading Animal Production Research Unit flock and were subject to the same general management regimen as the main flock. Ewes were kept on pasture with free access to water at all times. Sixty adult Mule (Blue-faced Leicester $\times$ Swaledale) ewes (mean liveweight $71.7 \pm 0.73 \mathrm{~kg}$ ) were divided into three treatment groups in the late anoestrous period (early August). Group 1 ewes $(n=30)$ were given primary immunization ( 2 s.c. sites in the hind axillary regions) with $600 \mu \mathrm{g}$ bI $\alpha(1-29)-\mathrm{Tyr} 30-\mathrm{PPD}$ conjugate per ewe emulsified with 2 volumes of Freund's complete adjuvant. Booster immunizations (200 $\mu \mathrm{g}$ conjugate per ewe emulsified with Freund's incomplete adjuvant) were given 5 and 10 weeks later. A further 15 ewes (Group 2) were immunized with PPD alone ( $450 \mu \mathrm{g}$ per ewe emulsified in Freund's complete adjuvant for primary immunization; $150 \mu \mathrm{g}$ per ewe in Freund's incomplete adjuvant for booster injections 5 and 10 weeks later) and thus represented carrier-immunized controls. The remaining 15 animals (Group 3) served as nonimmunized controls. Synchronization of oestrus was effected 10 days after the second booster immunization by insertion of intravaginal progestagen-containing polyurethane sponges (Veramix: Upjohn Limited, Animal Health Division, Crawley, West Sussex, UK) for 13 days, and 12 days after sponge removal, assessment of ovulation rate was carried out by laparoscopy. Blood samples $(5 \mathrm{ml})$ were taken from all ewes by jugular venepuncture immediately before primary and booster injections, and just before laparoscopic examination.

Immediately after laparoscopy, fertile Suffolk rams $(n=6)$ fitted with raddle harnesses equipped with wax crayon blocks were introduced to the ewes' enclosure. Ewes were inspected every 2 days for raddle marks and approximate dates of oestrus recorded. Owing to lack of pasture, the diet was supplemented at this time by feeding barley (200$300 \mathrm{~g}$ per ewe day ${ }^{-1}$ ) for two weeks, commencing 2-3 days before laparoscopy. Conception rates (the proportion of 
ewes that did not show a return to oestrus) and pregnancy rates (the proportion of ewes bearing at least one fetus when scanned ultrasonographically 11 weeks later) were also recorded. In late March, ewes were transferred to indoor lambing enclosures to await parturition. For each group, the proportion of ewes lambing, total number of lambs born per ewe, number of dead lambs born per ewe and lamb birthweight were recorded.

\section{Assessment of antibody titres}

Plasma samples were tested for their ability to bind ${ }^{125}$ I-labelled bovine inhibin $\left(\mathrm{M}_{r} 32000\right)$ isolated by Knight $e t$ al. (1987) and radiolabelled as described elsewhere (Knight et al., 1989). Incubation of diluted (1:1000) plasma samples with the tracer (approximately 10000 c.p.m. per tube), in a final volume of $200 \mu \mathrm{l}$, was carried out at room temperature for a period of $24 \mathrm{~h}$. Separation of antibody-bound tracer from free tracer was achieved using a preprecipitated second antibody reagent containing donkey anti-sheep IgG serum, normal sheep serum and 4\% (w/v) polyethylene glycol. Samples were centrifuged, and after aspiration of the supernatant, the precipitated antibodybound ${ }^{125}$ I-labelled tracer was counted using a multigamma counter. After correcting for nonspecific binding (recorded in the absence of sheep serum/antiserum), results were expressed as percentage binding relative to the total counts per tube.

\section{Determination of hormone concentrations}

Plasma concentrations of FSH were assessed using a homologous ovine FSH radioimmunoassay kit provided by NIDDK (Bethesda, MD, USA). Intra- and interassay coefficients of variation were $7 \%$ and $8 \%$, respectively, and the detection limit of the assay expressed as the amount of FSH standard required to inhibit the binding of the iodinated tracer (NIADDK-oFSH-I1) to the antibody (NIADKK-anti-oFSH-1; final dilution 1:16000) by 20\% was 37 pg per tube (equivalent to $0 \cdot 37 \mu \mathrm{g}^{-1}$ ).

Determination of plasma concentrations of $\mathrm{LH}$ was made using the radioimmunoassay described by Walton $e t a l$. (1977). Intra- and interassay coefficients of variation were $9 \%$ and $13 \%$, respectively. The limit of detection of the assay (expressed as the amount of the LH standard (NIH-LH-S16) needed to inhibit the binding of ${ }^{125}$ I-labelled LH to the antibody by $20 \%$ ) was $114 \mathrm{pg}$ per tube (equivalent to $1 \cdot 14 \mu \mathrm{g} \mathrm{l}^{-1}$ ).

\section{Statistical analysis}

Chi-squared analysis and Student's unpaired $t$ test were both used to evaluate the effect of immunization on ovulation rate and number of lambs born per ewe. Between-group comparisons examining the effects of immunization on gestation period, lamb birthweight and plasma concentration of FSH and LH were carried out using Student's unpaired $t$ test. Where indicated, Student's paired $t$ test was used to make within-group comparisons of time-dependent changes in mean plasma concentrations of FSH and anti-inhibin titres during the immunization programme.

\section{Results}

In December, one ewe from the inhibin-immunized group died (cause of death not established) and one of the PPD-immunized animals suffered a fractured leg and hence was excluded from the study.

\section{Plasma anti-inhibin titres and concentrations of FSH and LH}

Antibodies that bound ${ }^{125}$ I-labelled bovine inhibin $\left(\mathrm{M}_{r} 32000\right)$ were produced by all ewes receiving the bIa(129)-Tyr30-PPD immunogen, titres rising from very low levels after the first booster to a mean value of $16 \cdot 3 \pm 1 \cdot 4 \%$ (at 1:1000 dilution) after the second booster injection (Fig. 1). In neither PPD-immunized nor nonimmunized ewe plasma was any binding of ${ }^{125}$ I-labelled bovine inhibin detectable above the level seen in nonspecific binding (buffer only) tubes.

The data for PPD-immunized and nonimmunized animals have been combined as there were no significant differences in FSH concentration between these two control groups. A significant increase $(30 \% ; P<0.001)$ in mean plasma concentrations of FSH over mean preimmunization levels was seen 10 days after the second booster immunization in inhibin-immunized ewes but not in control animals (Fig. 1). Concentrations of plasma FSH in inhibin-immunized ewes both 5 weeks after the first booster and 10 days after the second booster immunization were significantly higher $(25 \%, P<0.025)$ than in the corresponding plasma samples from control ewes. In contrast, 


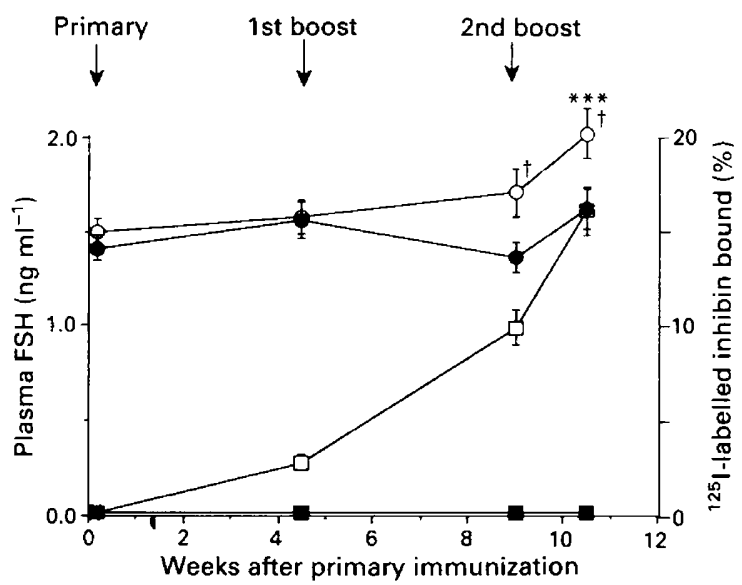

Fig. 1. Plasma concentrations of follicle-stimulating hormone (FSH) in 30 ewes during active immunization against a synthetic peptide corresponding to the $\mathrm{N}$-terminal sequence ((1-29)Tyr30) of the $\alpha$-subunit of bovine inhibin ( $\bigcirc$ ) and in 30 control ewes $(\odot)$. Fifteen of the control ewes were immunized with the carrier protein alone, while the remaining ewes received no treatment. Plasma anti-inhibin titres in inhibin-immunized $(\square)$ and control $(\boldsymbol{\square})$ ewes were assessed by incubating diluted (1:1000) plasma samples with ${ }^{125}$ I-labelled bovine inhibin $\left(M_{\mathrm{r}} 32000\right)$. Values are means \pm SEM.

$* * * P<0.001$ compared with preimmunization value.

$\dagger P<0.025$ compared with corresponding values in controls.

mean concentrations of plasma LH did not differ significantly between inhibin-immunized and control animals at any time during the experiment although there was a tendency for $\mathrm{LH}$ concentration to be lower (approximately 16\%) in the immunized ewes (data not shown). Mean plasma LH concentrations in the two control groups were not significantly different.

\section{Ovulation rates}

There was no significant difference between mean ovulation rates in the PPD-immunized $(2 \cdot 21 \pm 0 \cdot 24$, range $1-4)$ and the nonimmunized $(1 \cdot 93 \pm 0 \cdot 21$, range $1-3)$ control animals and the values obtained for these two groups were therefore combined (Table 1). The inhibin-immunized group had a mean ovulation rate significantly higher $(3.90 \pm 0.33$, range $1-8 ; P<0.005)$ than that of the combined control group $(2.07 \pm 0 \cdot 16$, range $1-4)$. No correlation $(r=0.23, P=0.14)$ was found to exist between ovulation rate and inhibin antibody titre in individual inhibin-immunized ewes.

\section{Conception, pregnancy and lambing rates}

The results for PPD-immunized (Group 2) and nonimmunized (Group 3) ewes were combined since they did not differ significantly from each other. In both inhibin-immunized and control groups, all ewes were fertilized and subsequently deemed to be pregnant approximately 11 weeks later; only one animal (in the control group) failed to produce at least one lamb (Table 2). There was no difference between the two groups in the mean length of gestation. The mean number of lambs born per ewe in the inhibin-immunized group $(2 \cdot 69 \pm 0 \cdot 27$, range $1-8)$ was significantly higher $(P<0.05)$ than in controls $(1.97 \pm 0.12$, range $0-3)$ (Table 3$)$, although a higher proportion of lambs in the inhibin-immunized group were born dead $(15.4 \%$ of the total, compared with $0.02 \%$ in control animals). Consequently, there was no significant difference between the two groups in the number of viable lambs (inhibin-immunized: $2.28 \pm 0.21$; controls: $1.93 \pm 0.11 ; P>0.05$ ). In 


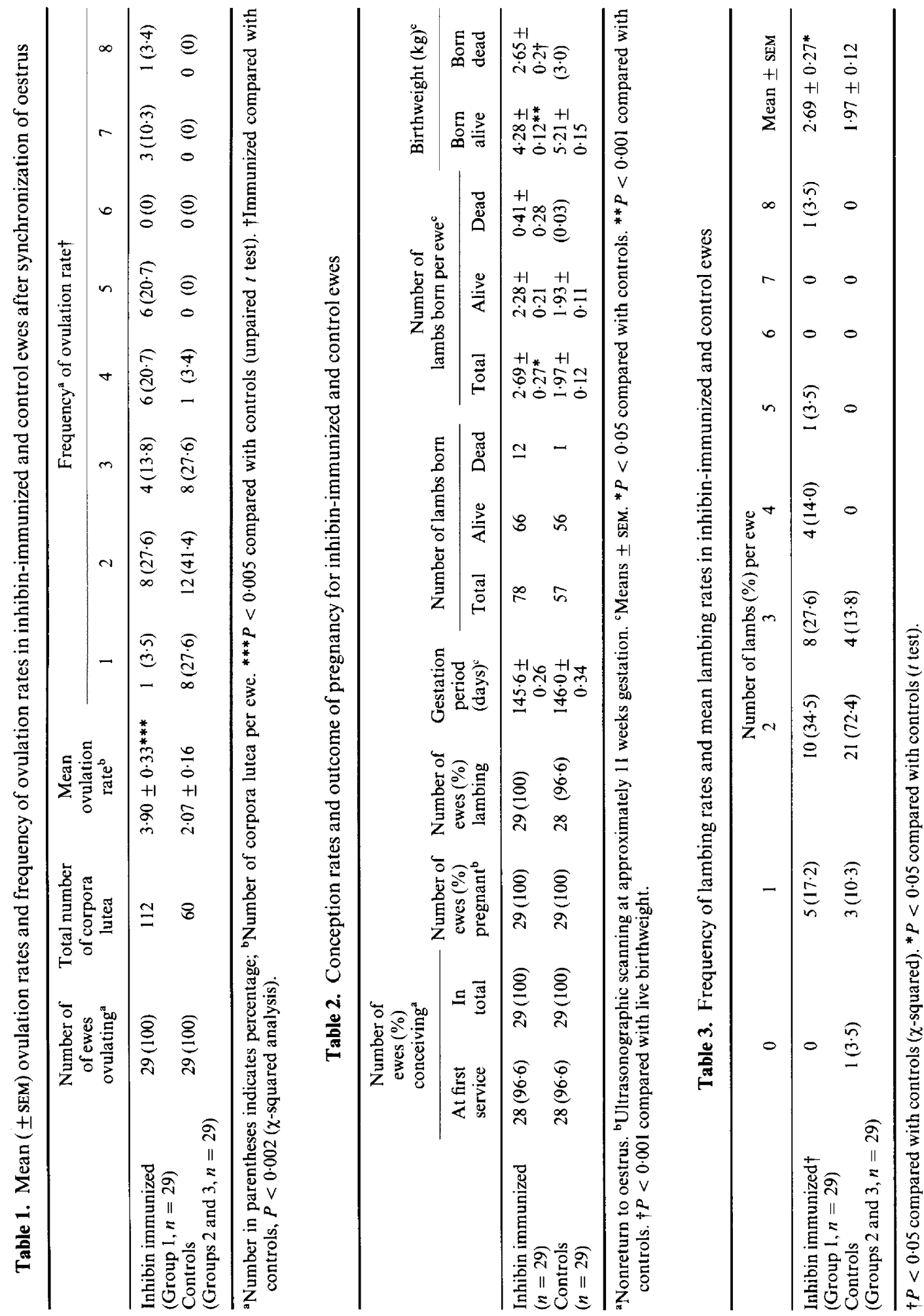


addition, mean live birthweight was significantly lower $(P<0.001)$ in the inhibin-immunized group $(4.28 \pm 0.12 \mathrm{~kg})$ than in controls $(5.21 \pm 0.15 \mathrm{~kg})$, whereas within the immunized group itself, lambs born dead weighed significantly less $(P<0.001)$ than those born alive (Table 2$)$.

\section{Discussion}

This study confirms and extends previous reports that active immunization of sheep against inhibin-containing preparations including partially purified bovine follicular fluid (Henderson $e t$ al., 1984; O'Shea et al., 1984; Cummins et al., 1986), recombinant DNA-derived inhibin subunits (Forage et al., 1987; Tsonis et al., 1989; Mizumachi et al., 1990) and chemically synthesized fragments of inhibin (Wrathall et al., 1990) can promote substantial (2-4-fold) increases in ovulation rate. It was demonstrated that the plasma of ewes immunized against a synthetic fragment of the $\alpha$ subunit of inhibin contained antibodies that bound ${ }^{125} \mathrm{I}$-labelled native bovine inhibin $\left(M_{\mathrm{r}} 32000\right)$, such antibodies being absent in nonimmunized and carrier-protein-immunized control ewes. Plasma anti-inhibin titres recorded here were very similar to those observed in our previous study involving administration of the same immunogen to ewes of a different (Romney) breed (Wrathall et al., 1990), demonstrating the consistency of the immune response to this synthetic peptide-based vaccine. As in this earlier study, no correlation was found between inhibin antibody titre and ovulation rate of individual ewes, an observation which is consistent with the report of Forage $e t$ al. (1987) but contradicts the recent findings of Tsonis et al. (1989).

In view of the conflicting evidence about whether active immunization against inhibin actually raises FSH secretion (Henderson et al., 1984; O'Shea et al., 1984; Cummins et al., 1986; Al-Obaidi et al., 1987; Findlay et al., 1989; Wrathall et al., 1990), it is still not possible to state unequivocally that the increased ovulation rate observed in inhibin-immunized ewes is due to a rise in plasma FSH levels, which would be a predicted consequence of inhibin immunoneutralization. The present study, however, provides further evidence to support this explanation since plasma FSH levels were significantly higher $(25 \%)$ than in control ewes after the second booster immunization, whereas plasma LH levels did not differ significantly between immunized and control ewes. The present findings are therefore consistent with our earlier study (Wrathall et al., 1990), which found a similarly modest (approximately 22\%) increase in plasma FSH after inhibin immunization. In this earlier study, more detailed examination of plasma hormone profiles revealed that plasma FSH concentration in inhibin-immunized ewes remained higher than in controls throughout the follicular phase of the cycle, a finding susbsequently confirmed by Mizumachi et al. (1990) and Wheaton \& Carlson (1990). It is noteworthy that both the magnitude of the increase in plasma FSH concentration (approximately $25 \%$ ) and the accompanying increase in ovulation rate (approximately twofold) observed by us following immunization against the same immunogen were very similar in Romney (Wrathall et al., 1990) and Mule (this study) ewes despite the twofold difference in spontaneous ovulation rate characteristic of these breeds. This observation suggests that the ovulatory response to inhibin immunoneutralization may, to some extent, be independent of spontaneous ovulation rate.

The present study revealed that active immunization against a synthetic inhibin fragment had no adverse effects on fertility (conception rate) and did not alter mean gestation length (146 days). After introduction of fertile rams, all but two ewes (one from each group) conceived at first mating with the remainder conceiving at second mating. It may be assumed, therefore, that all ewes showed behavioural oestrus indicative of a normal preovulatory positive feedback relationship between oestradiol and LH. Ultrasonic scanning at approximately 11 weeks' gestation provided confirmation that all immunized and control ewes were pregnant although it was not possible to ascertain the number of fetuses per ewe when this was judged to exceed two. All ewes, with the exception of one from the control group, gave birth to at least one lamb, mean lambing rate being $37 \%$ greater $(P<0.05)$ in the inhibin-immunized group than in the controls. It is clear, however, that the proportion of corpora lutea that resulted in lambs was considerably less for inhibin-immunized $(70 \%)$ 
than for control (95\%) ewes (see Table 2). This indicates a greater incidence of wastage of ova, embryos, or both, in the inhibin-immunized group, which is presumed to be a direct consequence of the substantially higher $(90 \%)$ ovulation rate shown by these ewes and not due to any adverse effect of inhibin immunoneutralization per se. In support of this view, Ashworth et al. (1989) have shown that embryo survival (to day 30) in ewes of the prolific 'Damline' breed is inversely related to spontaneous ovulation rate, declining steeply from about $80 \%$ when ovulation rate is $1-3$ to about $30 \%$ when ovulation rate is $4-5$. Moreover, Tsonis et al. (1989) reported that active immunization against inhibin in Border Leicester $\times$ Merino ewes (spontaneous mean ovulation rate $=1.4$ ) increased ovulation rate $3 \cdot 6$-fold, but resulted in only a twofold increase in lambing rate, again indicating an increased incidence of wastage of ova, embryos, or both. Thus, there may be relatively little scope for increasing mean lambing rates much beyond about 2.5 lambs per ewe, making the present technique involving inhibin immunoneutralization more applicable to breeds of lower prolificacy such as the Border Leicester $\times$ Merino ewes studied by Tsonis et al. (1989).

A discouraging finding of the present study was the greater mortality of lambs born to inhibinimmunized ewes, with 12 out of 78 lambs $(15.4 \%)$, compared with 1 out of 57 in the control group, either born dead or found to be dead within $1 \mathrm{~h}$ of birth. However, of the 12 dead lambs born to immunized ewes, eight were from a single ewe. As a consequence of their increased litter size, mean live birthweight of lambs was significantly less $(18 \% ; P<0.001)$ for inhibin-immunized ewes than controls, while, within the immunized group, lambs born or found dead weighed considerably less $(38 \% ; P<0.001)$ than viable lambs. No details of lamb mortality or birthweight were given by Tsonis et al. (1989) in their report of a comparable experiment involving Border Leicester $x$ Merino ewes immunized against a recombinant inhibin-based vaccine. However, it might be anticipated that the incidence of lamb mortality would be less than that recorded in the present study with ewes of the Mule breed owing to the inherently lower prolificacy (about 1.15 lambs per ewe) of the Border Leicester $\times$ Merino ewe.

We thank T. R. Morris, M. J. Bryant, W. E. Baldwin and T. R. Bevan (University of Reading Animal Production Research Unit), E. C. Bleach and M. Williams (IGER, Hurley) and A. J. Beard (Department of Biochemistry and Physiology) for their invaluable help with this study. We are also grateful to NIDDK for provision of radioimmunoassay reagents, S. Dalton for typing the manuscript and AFRC (Grant Number AG45/343) for financial support.

\section{References}

Al-Obaidi, S.A., Bindon, B.M., Findlay, J.K., Hillard, M.A. \& O'Shea, T. (1987) Plasma follicle stimulating hormone in Merino ewes immunized with an inhibinenriched fraction from bovine follicular fluid. Animal Reproduction Science 14, 39-51.

Ashworth, C.J., Sales, D.I. \& Wilmut, T. (1989) Evidence of an association between the survival of embryos and the periovulatory plasma progesterone concentration in the ewe. Journal of Reproduction and Fertility 87, 23-32.

Bradford, G.E. (1985) Selection of litter size. In Genetics of Reproduction in Sheep, pp. 3-12. Eds R. B. Land \& D. W. Robinson. Butterworths, London.

Cummins, L.J., O'Shea, T., Al-Obaidi, S.A., Bindon, B.M. \& Findlay, J.K. (1986) Increase in ovulation rate after immunization of Merino ewes with a fraction of bovine follicular fluid containing inhibin activity. Journal of Reproduction and Fertility 77, $365-372$.

Findlay, J.K., Doughton, B., Robertson, D.M. \& Forage, R.G. (1989) Effects of immunization against recombinant bovine inhibin $\alpha$ subunit on circulating concentrations of gonadotrophins in ewes. Journal of Endocrinology 120, 59-65.

Forage, R.G., Brown, R.W., Oliver, K.J., Atrache, B.T., Devine, P.L., Hudson, G.C., Goss, N.H., Bertram, K.C., Tolstoshev, P., Robertson, D.M., de Kretser, D.M., Doughton, B., Burger, H.G. \& Findlay, J.K. (1987) Immunization against an inhibin subunit produced by recombinant DNA techniques results in increased ovulation rate in sheep. Journal of Endocrinology 114, R1-R4.

Gheraradi, P.B., Lindsay, D.R. (1980) The effect of season on the ovulatory response of Merino ewes to serum from pregnant mares. Journal of Reproduction and Fertility 60, 425-429.

Henderson, K.M., Franchimont, P., Lecomte-Yerna, M.J., Hudson, N. \& Ball, K. (1984) Increase in ovulation rate after active immunization of sheep with inhibin partially purified from bovine follicular fluid. Journal of Endocrinology 102, 305-309.

Knight, P.G., Castillo, R.J. \& Glencross, R.G. (1987) Isolation from bovine follicular fluid (bFF) of a 32 $\mathrm{kDalton}$ molecule with potent inhibin-like biological 
activity (ILA). Journal of Endocrinology 112 (Supplement), Abstract 52.

Knight, P.G., Beard, A.J., Wrathall, J.H.M. \& Castillo, R.J. (1989) Evidence that the bovine ovary secretes large amounts of monomeric inhibin $\alpha$-subunit and its isolation from bovine follicular fluid. Journal of Molecular Endocrinology 2, 189-200.

Land R.B., Morris, B.A., Baxter, G., Fordyce, M. \& Forster, J. (1982) Improvement of sheep fecundity by treatment with antisera to gonadal steroids. Journal of Reproduction and Fertility 66, 625-634.

Mizumachi, M., Voglmayr, J.K., Washington, D.W., Chen, C.-L.C. \& Bardin, S.W. (1990) Superovulation of ewes immunized against the human recombinant inhibin $\alpha$-subunit associated with increased pre- and post-ovulatory follicle-stimulating hormone levels. Endocrinology 126, 1058-1063.

O'Shea, T., Al-Obaidi, S.A., Bindon, B.M., Cummins, L.J., Findlay, J.K. \& Hilliard, M.A. (1984) Increased ovulation rate in Merino ewes and advancement of puberty in Merino lambs immunized with a preparation enriched in inhibin. In Reproduction in Sheep, pp. 335-337. Eds D. R. Lindsay \& D. T. Pearce. Australian Academy of Science, Canberra.

Scaramuzzi, R.J. \& Hoskinson, R.M. (1984) Active immunization against steroid hormones for increasing fecundity. In Immunological Aspects of Reproduction in Mammals, pp. 445-474. Ed. D. B. Crighton. Butterworths, London.
Tsonis, C.G., Borchers, C.E., Hungerford, J., Tierney, L., Pearson, M., Brown, R., Braid, G., Doughton, B., Greenwood, P.E., Findlay, J. \& Forage, R.G. (1989) Effects on ovulation and lambing rates after immunizing sheep with recombinant inhibin alpha subunit. Proceedings of the 8th Australian Biotechnology Conference pp. 444-447.

Walton, J.S., McNeilly, J.R., McNeilly, A.S. \& Cunningham, F.J. (1977) Changes in the concentrations of follicle-stimulating hormone, luteinizing hormone, prolactin and progesterone in the plasma of ewes during the transition from anoestrous to breeding activity. Journal of Endocrinology 75, 127-136.

Wheaton, J.E. \& Carlson, K.M. (1990) Ovulation rate and gonadotropin levels following luteolysis in sheep immunized against an inhibin fragment. Program and Abstracts of 72 nd Annual Meeting of Endocrine Society. Abstract 765.

Wrathall, J.H.M., McLeod, B.J., Glencross, R.G., Beard, A.J. \& Knight, P.G. (1990) Inhibin immunoneutralization by antibodies raised against synthetic sequences of inhibin $\alpha$-subunit: effects on gonadotrophin secretion and ovulation rate in sheep. Journal of Endocrinology 124, 167-176.

Ying, S.-Y. (1988) Inhibins, activins and follistatins: gonadal proteins modulating the secretion of folliclestimulating hormone. Endocrine Reviews 9, 267-293.

Received 18 February 1991 